\title{
The Importance of Measuring Fine Motor Skill in Early Children's Education
}

\author{
Hermito Gidion ${ }^{1}$ \\ ${ }^{1}$ Occupational Therapy Laboratory, Vocational Education Program, Universitas Indonesia. \\ *Email: hermito.gidion@ui.ac.id
}

\begin{abstract}
This study attempted to explain the level of fine motor abilities of preschool children. Researchers used a visual motor skill measurement instrument by Morrison F. Gadner, which is commonly used in psychology and mengadopi some of today's developed methods. This test does not justify a child's motor skills but rather focuses on efforts to improve teachers' instruction methods to stimulate children's motor skills and develop them further. Pebgujian was conducted on 80 preschool children from 167 children who met the test criteria in the early children's education (ECE) school environment. Children's motor ability, which was successfully explored in this study, refers to children's attention and concentration skills, cognitive aspects, hand-eye coordination, hand strength, and so on. The test results showed that the average age of a child's maturity is directly related to their visual motor ability. The higher a child's chronological age, the higher their motor ability, and a child's low chronological age would indicate some limitations to their motor development.Test results were then communicated to schoolteachers and the children's parents. The researchers provided the teachers some inputs to further develop their teaching methods based on fine motor skills, which include improving children's motor skills and eliminating their motor limitations so that they develop in accordance with their developmental age.
\end{abstract}

Keywords: visual motor skill, preschool children, chronological age

\section{Introduction}

Most parents long for their children to grow up healthy, intelligent, and independent. Children are expected to undergo normal physical, mental, social, and spiritual growth according to their developmental age. However, the most important aspect that gets special attention is children's motor development. Hennigger (2009) explains that movement is at the center of a child's life and is important in all aspects of child development. Meanwhile, according to Palmer (2001), motion elements consist of body parts, action (walking, jumping), space (near/far, up/down), quality (fast/slow, slow/sudden), and relationship (below/above). Therefore, in the beginning of a child's development, when the child is able to respond to their parents, moving their limbs and torso, crawling, learning to walk, and so on are not only a matter of concern but also a source of happiness for the parents.

As children enter preschool age, most parents expect to enroll them in schools that will provide enhanced cognitive, affective, and psychomotor skills. Cognitive development in school age is characterized by the mastery of several concepts such as shape and size, space, relationship, amount, and time (Turner, 1992). The parents then entrust the children to the school. This is clearly a mistake because the responsibility of child development cannot be left entirely to the school; it is responsible only for certain aspects depending on its function and role while other aspects are still part of parents' duties at home. Early childhood education (ECE) at this time requires the child's mastery of literacy for school readiness. Literacy includes reading, writing, speaking, and listening (Morisson, 2003). The most important issue is how teachers in schools and parents at home can work together according to their roles and functions to jointly provide support and affection for children to encourage their physiological, psychological, and sociological development. 


\subsection{Children's motor growth phase}

A child's growth phase is triggered by cephalo-caudal motion stimuli from the back of the head to the tailbone, forming a proximal-distal motion from the middle of the body to the fingers. Fine motor skills are those that require the ability to control small or smooth muscles to successfully execute certain skills (Sumantri, 2005). Motor growth is highly influential to children's learning ability. Parents should constantly, carefully, and continuously observe their child's growing motor development so that they can help stimulate and train their development in case of interruption or delays within the child.

Children's early motor growth phase is characterized by gross motor skills and fine motor skills. Rough motor skills are the ability to coordinate the movement of large muscles in the hands, the feet, and in the limbs. Meanwhile, gross motor skills pertain to abilities that can be observed early in the child's life as part of their growth and development. Generally, in normal growth, a two-year-old can already stand, walk, run, and jump. Rough motor skills are built from the toddler stage and will get better as the child gets older (Kurniasari, 2010).

Fine motor skills involve the organization of the use of small muscle groups such as the fingers and the hands, which are often required in skills that include the use of tools and objects or to control machines, such as typing, sewing, and others (Sumantri, 2005, p. 143). Similarly, Mahendra (Sumantri, 2005, p. 143) stated that fine motor skills are those that require the ability to control small/smooth muscles to execute certain actions successfully. Meanwhile, Magil (Sumantri, 2005, p. 143) noted that such a skill involves the coordination of nerve muscles that require high precision to succeed. This type of skill is often referred to as one that requires hand-eye coordination, of which writing, drawing, and playing the piano are examples.

\subsection{Basic motor skills of preschoolers}

Motor development refers to the progress of controlling physical movement through central nervous activity and nerve-muscle coordination (Hurlock, 1998). Children's motor skills consist of abusive and fine motor skills. The motor skills of children aged 4-5 years are more developed in terms of motor content, and after the age of five, smooth motor development occurs. According to Papalia (2008), children's bones and muscles are getting stronger, and their lung capacity is improving, allowing them to run, jump, and climb faster, farther, and better. According to Santrock (2011), the fine motor coordination of four-year-olds is on the rise and becomes more precise when performing fine motor activities, with the hands, arms, and body moving together under the better command of the eye.

The preschool pattern of learning is focused on many daily school activities. The role of teachers is very important in supervising the development of children's motor skills in school and is equally important as the role of parents, who must always monitor their children's development at home. Teachers must understand how to observe children's growth process, evaluate their growth rate, and apply methods and techniques to stimulate their motor growth. This is important for teachers because the activities that children participate in can affect their next stage of learning, including their ability to write as a fundamental movement in the learning process. Unfortunately, in reality, the community has very few trained teachers who correctly understand children's motor growth process in school.

\subsection{Implementation of motor-based teaching methods}

It is important for ECE teachers to master teaching methods to stimulate and improve children's motor development, which starts with knowing their motor profile. Sometimes, in ECE implementation in Indonesia, teachers are too focused on learning in terms of the knowledge aspect, which refers to a child's ability to read before starting primary school. The community still often evaluates the quality of ECE schools by measuring whether they succeed in enhancing children's reading ability after completing ECE. This is a clear mistake that society must correct.

The educational aspect of preschool children covers cognitive, affective, and psychomotor aspects that must be fully provided to the child by considering physical, psychological, intelligence, and social interaction skills. Therefore, it is highly important for teachers to be equipped with teaching methods based on the child's motor skills so that they can support the child's motor development for the learning process of other aspects, that is, cognitive and affective, and for sustainability in the next level of education, which is primary school.

\subsection{How does the Visual Motor Skills Test explain the child's motor profile?}

The Visual Motor Skills Test (TVMS) aims to determine preschoolers' fine motor skill profile, which includes ability (asset) and limitations (limitation). Based on the test results, the teacher can understand their students' fine motor profile and therefore intervene to improve their fine motor skills. In this paper, the authors focused on children's fine motor skills in terms of writing ability. Understanding writing includes a child's 
concentration and attention, response to commands, cognitive aspects, eye coordination (visual), hand gestures (motor), and physical endurance especially hand strength (grasping and pinching stationery) during their writing activities. Thus, writing ability can represent a child's visual-motor integration (VMI) and simultaneously reflects their fine motor development profile.

Sanghavi and Kelkar (2005) stated that VMI is the ability of the eyes and hands to work simultaneously in an efficient and smooth pattern to translate visual perception into motor function. There are now several test kits for children's VMI, such as Beery's Visual-Motor Integration Test (Kaiser 2009) and the Bender-Gestalt Test (Brannigan, Decker, \& Madsen, 2004). In their application, both test kits require the subject to redraw certain visual forms (usually line drawings or shapes) on paper using a pencil. However, unlike the two VMI tools, the Visual Motor Skills Test developed by this author combines VMI with several other motor elements that affect writing skills.

Lamme (Desai \& Rege, 2005) noted that certain factors affect writing skills, such as small muscle development, hand-eye coordination, stationery manipulation, making simple shapes or scribbles, introducing letters, and knowledge of language in writing. A child reaches the VMI stage when they coordinate the ability of the eyes and hands to work simultaneously in an efficient and subtle pattern to turn visual perception into motor function in simple forms and translate such knowledge of form into writing. Therefore, motion in fine motor skills does not require power but does require careful and meticulous coordination (Depdiknas, 2007).

\section{Literature Review}

Developmental literature indicates that early life experiences and interaction, including stimulation of senses, have the greatest influence on brain development during the first three years of life (O'Brien Caughy, Huang, Miller, \& Genevro, 2004). This is the period where visual and visual perceptual skills develop (O'Brien Caughy, et al., 2004) and is the foundation phase for gross and fine motor development.

VMI is an important component in children's development (Coallier \& Rouleau, 2014). It is linked to many functional skills and the ability to participate in daily tasks (Marr \& Cermak, 2002). For example, VMI appears to play an important role in the development of handwriting (Volman, van Schendel, \& Jongmans, 2006). Feder and Majnemer (2007) described handwriting as a "complex perceptual-motor skill encompassing a blend of visual-motor coordination abilities, motor planning, cognitive, and perceptual skills, as well as tactile and kinesthetic sensitivities" (p. 313). VMI consists of coordinating visual perceptual skills with gross motor movement and fine motor movement. It is the ability to integrate visual input with motor output. It pertains to how individuals plan, execute, and monitor motor tasks, such as threading a needle, tying shoelaces, and catching or hitting a ball and is also essential in academic performance. "VMI is the degree to which visual perception and finger-hand movements are well coordinated." (Beery \& Beery, 2010, p 12).

VMI also refers to the degree to which visual perception and finger-hand movements are well coordinated (Beery \& Beery, 2010). VMI also covers basic skills such as seeing and using objects, and it includes developmental skills such as crawling, walking, running, avoiding danger, and eating; academic skills such as drawing, painting, reading, and writing; and advanced intellectual skills such as using a computer, constructing buildings, using tools, and discovering things (Daly et al., 2003).

The normal development of visual skills and visual perception will also contribute to a child's VMI skills. Sensory stimulation and exposure to environmental factors enhance the development of VMI, visual perception, and motor coordination. Infants are stimulated by lines, light intensities, and different patterns of movement, which facilitate their perception of the world. They start to see color from age two to three months and learn spatial abilities from age three to four months. Their perception of spatial relations of objects occurs later with the development of their binocular vision and depth perception from age four months. Size and shape constancy also develops in infancy (Arterberry, 2008).

Motor coordination is the ability to combine body movements with kinematic and kinetic properties (space and force) to produce an intentional action (Daly et al., 2003). According to Daly et al. (2003), "[m]otor coordination is achieved when subsequent parts of the same movement, or the movements of several limbs or body parts are combined in a manner that is well timed, smooth, and efficient with respect to the intended goal." (Daly et al., 2003).

\section{Methodology}

This paper seeks to present an alternative approach to some visual motor skills testing models that have been proposed by the abovementioned experts. With reference to the previously mentioned theories, the author attempts to modify and adapt to the latest developments and apply them in a simple research model implemented on the research objects, that is, preschool children scattered in some early childhood schools in Cisarua village, 
Nagrak district, Sukabumi regency in West Java. This research is conducted simultaneously with the implementation of the DRPM UI community service program from May to October 2017.

This research adopts a qualitative descriptive approach. Descriptive research is a study conducted on independent variables where no comparisons or connections are made with other variables. This study uses a single variable, namely fine motor skills.

Prior to the execution of the study, the authors first designed a test instrument compiled in book form and titled "Visual Motor Skills Test (TVMS)" to be distributed to children for testing with the assistance of teachers in the classroom. The tasks performed by the authors in this study are as follows:

1) Observing the object of study

Before this research was done, the author had observed some objects of study for testing. From these observed objects, the writer chose the Cisarua village rural community, as the area represents the average condition of Indonesia's village community but also has characteristics commonly found in urban areas, especially on the island of Java.

2) Conducting sampling

Based on the selected study object, the authors conducted a sampling test of 167 preschool children at 13 ECE schools scattered in the study object area. The authors cooperated with the ECE teacher community and individual teachers through a socialization process for a consistent vision and perception to obtain similar perspectives, needs, and objectives of study.

3) Testing and measuring

Before the testing process, the researcher provided technical guidance to the teachers to administer the TVMS instruments to the children. With the supervision of the authors, the teachers independently guided and directed the children to use the test equipment according to instructions.

4) Data processing

Based on the test results, the authors performed data processing, data rectification, and interpretation of test results.

5) Presenting reports

The test results were then presented to the school as reports and given individually to parents.

6) Evaluating and following up

The author then conducted a meeting with the school to explain to teachers the profile of each child based on their assets and limitations and recommend teaching techniques to improve their fine motor skills in the next learning process.

\section{Results and Discussion}

Before TVMS testing, the authors determined that research objects would be preschool children's biodata including their name, gender, date of birth, chronological age (test), testing date, and dominant hand movement (right/left). Such information is important to obtain a child's condition profile in accordance with test criteria. Tests were conducted on 167 children spread across 12 ECE schools in Cisarua village, Nagrak subdistrict, Sukabumi district. Testing was done in the classroom with the help of teachers who were guided on how to administer the test. The time required for testing was limited to 30 minutes. Time duration was determined based on matters settled per minute, with as many as 26 questions can be answered within the whole period, with a four-minute leeway for technical needs. Problems were provided in the form of a line or two-dimensional images with certain variation. Each question has a score range of values between 0 and 2 with a maximum score of 48 . The children were asked to copy or imitate the image and rewrite the object in the column/space provided in the TVMS book. Then, based on the results of the children's work, the researchers provided a range of assessments according to their ability: very good, good enough, and needs improvement. This test has been designed as necessary to explore the children's fine motor skills. Its purpose was to reveal two aspects: the child's state of asset/fine motor ability according to their age and limitations that they may still possess. The criteria for measuring the child's visual motor ability include the following:

1) Attention and concentration: children's ability to focus their attention to the teacher's instructions when explaining the workmanship task guide

2) Understanding (cognitive aspect): children's ability to understand the content of the teacher's commands and to apply it in their motor activity

3) Hand-eye coordination: visual ability and hand movements that are mutually supportive when the child starts to perform writing movements

4) Fine motor visual skills: the child's ability to apply fine motor aspects consistently when doing writing movements 
5) Coordination of two hands (bilateral coordination): the ability of both the right and left hand to coordinate according to their function when the child is writing; for example, the dominant hand is used for writing while the other hand is used to maintain the balance of the body

6) Coordination of one hand (lateral coordination): the ability of the dominant hand to perform writing activities consistently

7) Grasping power (hand grasp): the ability of the dominant hand to hold a writing instrument

8) Clamping force (pinch): the strength of two fingers in holding the stationery in place

9) Three-jaw chucks: the ability to balance and coordinate the three fingers used during writing activities

Based on the test results of 80 children who met the criteria, ujia obtained three groups with the following assessment scores:

1) Children who scored 24 points and above

This group consisted of 15 children (19\%) whose highest score was 39 and lowest score was 24. They generally possess the following criteria:

- Abilities (Assets)

Their attention and concentration are good enough. Their ability to understand the instructions is also adequate, and their understanding the concept of form is quite good.

- Limitations

Their fine motor skills have not been consistently good and optimal, Their ability to grasp is also not ideal in terms of writing ability, as they get easily tired when writing for prolonged periods. Their hand-eye coordination is not optimal. Their cognitive function in understanding is quite good, however.

2) Children who scored $12-24$ points

There were 48 children $(60 \%)$ in this group, whose highest score was 23 and lowest score was 12. Generally, they meet the following criteria:

- Abilities (Assets)

Their attention skills and ability to concentrate are quite good. Their comprehension of the instructions is also sufficient.

- Limitations

Their fine motor abilities are not optimal, and their ability to grasp while writing has also not been ideal, since they easily feel tired when doing it for extended periods. Their hand-eye coordination is not optimal as well. Nevertheless, their cognitive skills are quite good.

3) Children who scored below 12 points

This group had a total of 17 children (21\%), with 11 being the highest score and 3 the lowest. They meet the following criteria:

- Abilities (Assets)

Their attention and concentration are satisfactory. Their ability to understand instructions is quite good as well.

- Limitations

Their fine motor skills are not yet optimal, and so is their grasp strength when writing, as the children get tired right away when writing for long periods. Their hand-eye coordination is also deficient. Their cognitive ability to understand the concept of form has not been good as well.

The test results are an important concern for teachers or parents to help children overcome their limitations and develop their assets or abilities. Therefore, based on the TVMS results above, researchers disseminated this information to the ECE school and the teachers. It is important to inform the school that the test results are not intended to solely assess whether the child's motor skills are good or bad but rather to improve and refine the teaching methods in the classroom to focus more on improving and developing the child's fine motor skills. The following are some of the researchers' recommendations to the school:

1) Children who scored 24 points and above

- There is no significant limitation of the children's fine motor skills.

- There is a need to develop their ability to perform tasks using the right and left hands to work on writing activities with a higher level of kesulitas.

- Activities using three-jaw chucks (grasping with the index finger and middle finger) need to be provided more intensively for an optimal writing ability that is in accordance with their developmental stage.

2) Children who scored 12-24 points

- Children's ability to perform activities using the right and left hands, from the easiest to the most difficult, needs to be optimized.

- Activities using three-jaw chucks need to be provided so that their writing ability is optimal and consistent with their developmental level. 
3) Children who scored below 12 points

- Their cognitive abilities and shape concepts, from the easiest to the most difficult, need to be optimized as well.

- The children need to understand the concept of form when performing activities using the right and left hand, from the easiest to the hardest.

- They need to participate in activities using three-jaw chucks so that their writing ability is adequate and in accordance with their developmental stage.

To facilitate the application of teaching methods based on these recommendations, the researchers provided technical training to teachers to improve and develop children's motor skills through classroom and out-of-class learning activities such as folding, cutting, choosing colors, coloring drawings, installing or matching objects, regular gymnastics, and so forth.

\section{Conclusion}

The child's motor skills will usually evolve according to their growth phase. However, parents and teachers should monitor and pay attention to each child's motor skills, as every child is unique and has different abilities and limitations. Therefore, in the process of monitoring children's growth and development, parents and teachers should look at what ability (asset) should be developed further and find out the limitations of children who should receive special attention. Supervision cannot be done through momentary activities but must be rather consistent with the focus on children's daily activities either at home or at school. TVMS is one of the tests conducted to know the extent of children's fine motor skills development in writing activities. By adopting several experts' theories about integrated visual motor skills, the researchers attempted to apply the test to preschool children in an ECE school environment to understand their fine motor profiles.

Based on the test results, it can be concluded that a child's motor skills develop in accordance with their age. The higher their chronological age, the higher their score. In addition, no gender differences were found to affect the children's scores. Children who have high scores possess no limitations, but their abilities must continuously be developed. Scores considered "good" need to be improved and would require parents' and teachers' special attention and application of some of the researchers' recommendations.

Knowing the motor skills profile in a child's growth is vital to their learning ability. Parents and teachers should be involved in monitoring child development. TVMS became a test that can determine a child's skill profile. Through this test, ECE schools can obtain a profile of their students' motor abilities. This test is excellent for use by ECE schools since it enables schools and teachers to evaluate teaching methods with reference to the child's motor skills profile. Furthermore, this test needs to be developed further by enriching the instruments and considering other variables to capture a more detailed profile of a child's motor skills. Meanwhile, the limitation of this test is that it only focuses on fine motor skills related to writing ability. Therefore, other types of activities emphasizing the child's fine motor skills would need to be developed further.

\section{Acknowledgments}

The authors would like to express their endless gratitude to DRPM UI, which provided them the opportunity to conduct research amid the demands of the implementation agenda of community service programs. Appreciation is also conveyed to the Vocational Education Program of the University of Indonesia, which has enabled the authors to enghadiri as well as present this paper.

\section{References}

Henniger, M. L. (2009). Teaching Young Children (4th ed.). New Jersey: Pearson Education, Inc.

Karlsdottir, R., \& Stefansson, T. (2002). Problems in developing functional handwriting. Perceptual and Motor Skills, 94(2), 623-662.

Kurniasari, Diyah, (2010). Pendekatan pembelajaran Beyondcenter and circle Time (BCCT) di sentra persiapan dalam upaya persiapan menulis dasar, (online), (http://etd.eprints.ums.ac.id/9830/1/A520085029.pdf, diakses tanggal 15 april 2108).

Marr, D., \& Cermak, S. (2002). Predicting handwriting performance of early elementary students with the developmental test of visual-motor integration. Perceptual and Motor Skills, 95(2), 661-669.

Marr, D. A. (2002). Fine motor skills in young children (Order No. 3067195). Available from Nursing \& Allied Health Database; ProQuest Dissertations \& Theses Global. (304790803). Retrieved from https://remotelib.ui.ac.id:2078/docview/304790803?accountid=17242

Morrison, G. (2009). Early Childhood Education Today (11th ed.). New Jersey: Pearson Education, Inc. 
O'Brien Caughy, M., Huang, K., Miller, T. \& Genevro, J. (2004). The effects of the Healthy steps for young children program: Results from observations of parenting and child development. Early Childhood Research Quarterly, 19(4), 611-630.

Palmer, H. (2001). The Music, Movement, and Learning Connection. Young Children, 56(5), 13-17.

Papalia, D., \& Fedlman, R. (2012). Experience Human Development (12th ed.). New York: McGraw-Hill.

Santrock, J, W. (2011). Child Development 13th edition. New York: Mc-Graw Hill.

Sumantri. (2005). Model Pengembangan ketrampilan Motorik Anak Usia Dini. Jakarta: Departemen Pendidikan Nasional.

Turner, J. S., \& Donald, B. H. (1995). Lifespan Development (5th ed.). USA; Wardworth.

Volman, M. J. M., van Schendel, B., \& Jongmans, M. J. (2006). Handwriting difficulties in primary school children: A search for underlying mechanisms. American Journal of Occupational Therapy, 60(4), 451-460. 